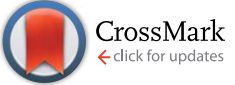

Cite this: RSC Adv., 2017, 7, 4983

\title{
Regeneration of an efficient, solar active hierarchical ZnO flower photocatalyst for repeatable usage: controlled desorption of poisoned species from active catalytic sites $\dagger$
}

\begin{abstract}
K. S. Ranjith ${ }^{a}$ and R. T. Rajendra Kumar*ab
To date, reusable properties of nano photocatalysts (PCs) have been investigated for five to ten consecutive cycles with a mild decrease in photocatalytic performance. Systematic investigation on the decrease in photocatalytic performance and regeneration of the nanocatalyst after repeatable usage have rarely been reported. Hierarchical forms of self-assembled zinc oxide $(\mathrm{ZnO})$ with a flower-like structure have been successfully synthesized by an aqueous solution based precipitation and show visible photocatalytic degradation efficiency of $98 \%$ against methylene blue (MB) dye in 120 min under natural solar irradiation and visible irradiation. Reusable catalytic properties were studied for 50 consecutive cycles and the degradation efficiencies obtained were around 85.9, 61.4, 47.3, 31.6 and 21.3\% in 120 min of photo irradiation for $10,20,30,40$ and 50 consecutive repeatable cycles, respectively. On increasing the number of cycles, the photocatalytic efficiency of the $\mathrm{ZnO}$ flowers decreased due to adsorption of hydrocarbon molecules on the active sites of the catalyst, a phenomenon termed as catalytic poisoning. Furthermore, we show that the photocatalytic performance of $\mathrm{ZnO}$ hierarchical flowers could be completely reverted by a simple chemical treatment for further repeatable usage by removing the hydrocarbon groups on the active sites of the surface of the nanocatalysts. Our results provide insights into the effective visible photocatalytic nature and controlled process which removes the poisoning effect and regenerates the catalytic properties.
\end{abstract}

Received 26th November 2016 Accepted 30th December 2016 DOI: $10.1039 / \mathrm{c} 6 \mathrm{ra} 27380 \mathrm{~g}$ www.rsc.org/advances
Efficiency of the catalytic response has influence by the morphology as well as by the effective carrier separation and production of reactive oxygen species (ROS) over the catalytic surface. ${ }^{15}$ However, catalytic stability and multiple reusable properties of the nanocatalyst are the critical deciding factors for commercializing the AOPs for the environment remediation applications. Several investigations about catalytic loss, ${ }^{16-18}$ sulfur $^{19}$ and hydrocarbon impurities ${ }^{20}$ based poisoning of catalysts and regenerating the catalytic performances were described on gas phase oxidation of heptane, petroleum refining and photochemical based industries. ${ }^{20-22}$ Reusability of the nanocatalysts is the one of the important criteria for the utilization of nanocatalysts for environmental remediation applications. Re-using of nanocatalysts is vital owing to the rigid environmental safety regulations for their disposal and economic benefit. ${ }^{27}$ So far, majority of the reports show that reusable properties of $\mathrm{TiO}_{2}, \mathrm{WO}_{3}, \mathrm{ZnO}$ nanocatalysts were studied up to 10 cycles and further utility of the catalyst were not much clearly investigated..$^{18,23-26}$ To date, articles present reusability of the photocatalyst tested upto 5 to 10 cycles and report good reusability. However, detailed study on reusability (after multiple cycles) and stability of the photo catalyst is missing.

\footnotetext{
${ }^{a}$ Advanced Materials and Devices Laboratory, Department of Physics, Bharathiar University, Coimbatore, India. Fax: +91-422-2422387; Tel: +91-9894865562

${ }^{b}$ Department of Nanoscience and Technology, Bharathiar University, Coimbatore, India. E-mail: rtrkumar@buc.edu.in; Fax:+91-422-2422387; Tel: +91-9789757888

$\dagger$ Electronic supplementary information (ESI) available. See DOI: $10.1039 / \mathrm{c} 6 \mathrm{ra} 27380 \mathrm{~g}$
} 
Our previous article reports on morphology (rods, brooms, spindles, stars, needles, hierarchical flowers, multipods) controlled synthesis of $\mathrm{ZnO}$ nanostructures and inter-relation between their (i) morphology, (ii) surface defects (iii) ROS production and (iv) photocatalyst properties. ${ }^{15}$ Hierarchical $\mathrm{ZnO}$ nanoflowers show efficient PC performance compared to the other nanostructures and reusability of the same was studied upto 10 cycles.

In the present work, to get better insight on the catalytic stability and reusability, reusable properties of hierarchical $\mathrm{ZnO}$ flowers were studied extensively upto 50 cycles. The structural and functional properties of the reused hierarchical $\mathrm{ZnO}$ flower catalysts reveal that after multiple reusable cycles, catalytic surface were poisoned due to chemisorbed hydrocarbon groups on the active catalytic sites which termed as catalyst poisoning. A simple, cost effective, chemical treatment process has been proposed to regenerate the poisoned hierarchical $\mathrm{ZnO}$ flower catalyst to revert back to its maximum photocatalytic performance. The results could be useful for designing and processing of photocatalysts for repeatable usage.

\section{Experimental}

\section{Synthesis of hierarchical ZnO flowers}

All chemicals were purchased from Himedia and used without further purification. Growth parameters of hierarchical $\mathrm{ZnO}$ flowers are reported in detail in our previous publication. ${ }^{15}$ Briefly, equal mole of $\mathrm{Zn}\left(\mathrm{NO}_{3}\right)_{2} \cdot 6 \mathrm{H}_{2} \mathrm{O}$ and HMTA were taken in separate $150 \mathrm{~mL}$ beakers and stirred for $5 \mathrm{~min}$. After stirring, HMTA was added drop wise into $\mathrm{Zn}\left(\mathrm{NO}_{3}\right)_{2}$ precursor and stirred. After stirring for $10 \mathrm{~min}$ at room temperature, $10 \mathrm{~mL}$ of ammonia was mixed slowly into the solution. The solution was placed in a constant temperature bath and heated at $97^{\circ} \mathrm{C}$ for 4 hours. The samples were cleaned and centrifuged using distilled water and ethanol three to four times and baked at $100{ }^{\circ} \mathrm{C}$ for $30 \mathrm{~min}$.

\section{Characterization}

The phase and crystalline structure of the samples were studied using Phillip X'pert Pro Advance Powder X-ray diffractometer (Cu-K $\alpha$ radiation; $\lambda=1.5418 \AA$ ). The morphology of the nanostructures was studied by ZEISS scanning electron microscope. A JEOL JEM-2100 high resolution transmission electron microscope (HRTEM) operated at $200 \mathrm{kV}$ was used for the detailed microstructural characterization of the nanostructures. UV-Vis absorbance spectra of the samples were recorded using JASCO V620 UV-Vis spectrophotometer. A HORIBA JOBIN YVON spectro fluoromax-4/photoluminescence spectrophotometer was used for obtaining the photoluminescence spectra (PL) of the samples. The specific surface area (SSA) was evaluated using the Brunauer, Emmett, and Teller (BET) nitrogen adsorption method (Micromeritics ASAP 2030). Fourier's Transfer Infrared Spectrometer (FTIR) spectra were recorded by Bruker Tensor 27, spectrometer over the range $4000-400 \mathrm{~cm}^{-1}$ using $\mathrm{KBr}$ as the reference. UV-Vis DRS measurement was acquired using a JASCO V620 UV-Vis spectrophotometer. The surface analysis of the sample was carried out by using X-ray photoelectron spectroscopy (XPS). All binding energies were referred to the $\mathrm{C}$ 1s peak (284.6) arising from surface hydrocarbons (or adventitious hydrocarbons).

\section{Photocatalytic study}

The photocatalytic activity of $\mathrm{ZnO}$ was evaluated using Methylene Blue $(\mathrm{MB})$ as model contaminant. The reactions were performed under dark, UV light (30 W Hg lamp (ZF-1 UV, Philips, China), setup with peak emission at $\lambda=365 \mathrm{~nm})$, under visible irradiation (75 W xenon lamp with the UV cut off filter $(\lambda>400$ $\mathrm{nm}$ ) (Lee type 226 (USA))), under natural sunlight (sunlight, 905 Lm per $\mathrm{m}^{2}$ ) with the UV cut off filter (Lee type 226 (USA)) on a normal sunny day between 8.00 a.m and 4.00 p.m under the shadows in order to avoid the evaporation of solution through heat effect. The light intensity was constantly checked every 30 min using lux meter. ${ }^{15}$ In a photo reaction experiment, $100 \mathrm{mg}$ of $\mathrm{ZnO}$ was suspended in a $100 \mathrm{~mL}$ aqueous solution containing $15 \mathrm{mg} \mathrm{L}^{-1}$ of MB in neutral $\mathrm{pH}$. Prior to irradiation, the solution was stirred for $30 \mathrm{~min}$ in the dark to ensure establishment of an adsorption-desorption equilibrium on the surface of the PC. The absorbance behaviour of MB was monitored every $30 \mathrm{~min}$ with an overall reaction time of $180 \mathrm{~min}$ by UV-Vis spectrophotometer ranging from 200 to $800 \mathrm{~nm}$. The concentration of organic dyes was determined by measuring the absorption intensity at the maximum absorbance wavelength of the supernatant $(\mathrm{MB}=661 \mathrm{~nm}$ ) by using a UV-Vis spectrophotometer. Similar experiment was carried out without any photo illumination sources in order to measure the catalytic behaviour under dark. The degradation efficiency $(\eta)$ of the dye wastewater could be defined as follows. ${ }^{28}$

$$
\eta=\frac{C_{0}-C_{t}}{C_{0}} \times 100
$$

where $C_{0}$ is the initial dye concentration, $C_{t}$ is the dye concentration at a certain reaction time $t(\mathrm{~min})$. Catalytic efficiency of commercial $\mathrm{ZnO}$ (sigma Aldrich) was investigated and compared with the hierarchical $\mathrm{ZnO}$ flower catalyst. The poisoning effect due to absorbance of the dye molecules on the nano structural surface was studied using Tensor 27 Fourier's Transfer Infrared Spectrometer.

\section{Active species trapping, superoxide and hydroxy radicals quantification}

For detecting the active species during the photocatalytic reaction, hydroxyl radicals $\left({ }^{\circ} \mathrm{OH}\right)$, superoxide radicals $\left(\mathrm{O}_{2}{ }^{\circ}\right)$ and holes $\left(\mathrm{h}^{+}\right)$were investigated by adding $1.0 \mathrm{mM}$ IPA (isopropyl alcohol, a quencher of ${ }^{\circ} \mathrm{OH}$ ), BQ (benzoquinone, a quencher of $\mathrm{O}_{2}{ }^{\circ}$ ) and TEOA (triethanolamine, a quencher of $\mathrm{h}^{+}$), respectively. ${ }^{29}$ Nitroblue tetrazolium (NBT) $(100 \mathrm{mM}$, exhibiting an absorption maximum at $259 \mathrm{~nm}$ ), $p$-chlorobenzoic acid (CBA) (100 $\mathrm{mM}$, exhibiting an absorption maximum at $312 \mathrm{~nm}$ ) were used as the indicators to determine the amount of super oxide $\left(\mathrm{O}_{2}{ }^{-}\right)$and hydroxyl radicals $\left(\mathrm{OH}^{*}\right)$ generated from the nanocatalyst. NBT was stored for no longer than one day at $4{ }^{\circ} \mathrm{C}$. After UV illumination for different periods of time, $1 \mathrm{~mL}$ of the 
suspension was sampled and injected into a quartz vial. The concentration of NBT and $p$-CBA (the product resulting from the reduction of NBT and $p$-CBA by $\mathrm{O}_{2}{ }^{--}, \mathrm{OH}^{*}$ respectively) were measured using a UV-Vis spectrophotometer (JASCO 620) at $257 \mathrm{~nm}, 312 \mathrm{~nm}$ respectively. Exposure tests were run for different time periods, for up to $180 \mathrm{~min}$ as the photocatalytic degradation test, with NBT and $p$-CBA replacing the dye. ${ }^{\mathbf{3 0 - 3 2}}$

\section{Reusable photocatalytic properties}

Reusability tests were conducted for the hierarchical $\mathrm{ZnO}$ flowers. Briefly, the selected photocatalyst (after being used in degradation test of $\mathrm{MB}$ ) was allowed to settle down naturally in the reactor ( $\sim 30 \mathrm{~min})$. Because of it micro sized morphology it settles down fast and was rinsed thrice with distilled water. The washed material was then dried at $60{ }^{\circ} \mathrm{C}$ for 5 hours before using in a new MB degradation experiment. Fifty consecutive additional tests were conducted.

\section{Results and discussion}

ZnO structures of various morphologies such as rods, brooms, buds, spindles, stars, hierarchical flowers and multipods (Fig. S1, ESI $\dagger$ ) by simply controlling the Zn supersaturation in the growth solution. ${ }^{15}$ Reusable properties of $\mathrm{ZnO}$ structures revealed decrease in PC activity after 10 cycles. Among the various $\mathrm{ZnO}$ morphologies, hierarchical $\mathrm{ZnO}$ flowers ${ }^{\mathbf{1 5}}$ showed best photocatalytic activity (Fig. S2 and S3, ESI $\dagger$ ) and therefore chosen for elaborate reusable studies presented in this work.

\section{Crystal phase and morphology analysis}

The phase and crystallinity of the as-synthesized product was studied by XRD and the resultant XRD pattern is shown in Fig. 1. The intense and sharp diffraction peaks suggest that the product was highly crystalline and well matched with a standard data card (JCPDS-80-0075; $a=3.259 \AA$ and $c=5.209 \AA$ ) indexed as hexagonal phase $\mathrm{ZnO}$. The calculated lattice parameters are; $a=3.282 \AA$ and $c=5.249 \AA$. No other impurities

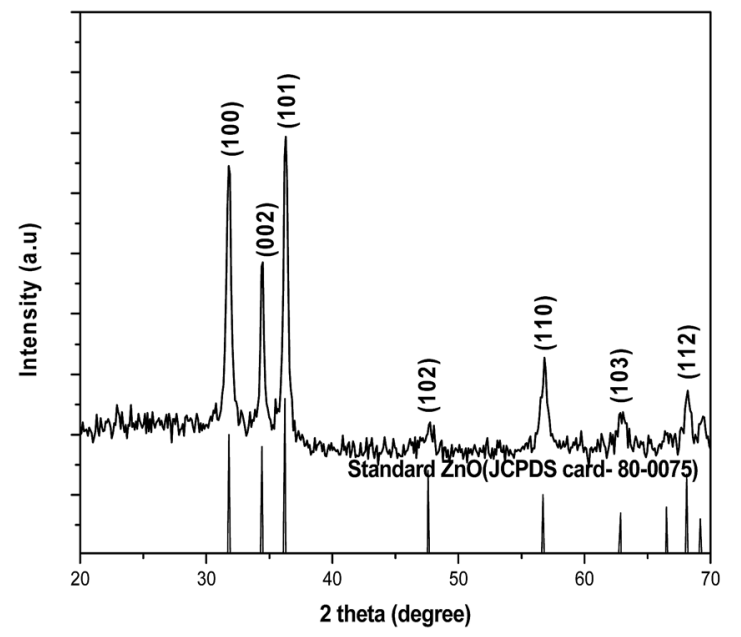

Fig. 1 XRD pattern of hierarchical $\mathrm{ZnO}$ flower catalyst. were detected, demonstrating that the products are of high purity with single crystalline phase. In addition, the width of the diffraction peaks indicate that the sample product comprises of smaller crystallites. Fig. 2a and inset shows the SEM images of hierarchical ZnO flowers with varying magnifications. Fig. 2a indicate that the product is composed of flower-like structure and has the dimension of 400-800 $\mathrm{nm}$ with multiple facets of size 80-100 $\mathrm{nm}$. As hierarchical structure of the as-synthesized $\mathrm{ZnO}$ is further elucidated by TEM studies (Fig. 2b-d), it is observed that the $\mathrm{ZnO}$ flowers comprise of needle like structures and nanoparticles of size about 200 and $15 \mathrm{~nm}$ respectively. Fig. $2 \mathrm{c}$ and $\mathrm{d}$ shows the HRTEM images of the assynthesized $\mathrm{ZnO}$ in which the cluster of nanograins are oriented and assembled to form a flower-like hierarchical architecture. The growth mechanism of the $\mathrm{ZnO}$ hierarchical flowers is beyond the scope of this paper, detailed growth mechanisms are reported in our previous publication. ${ }^{\mathbf{1 5}}$

\section{Elemental analysis}

In order to determine the elements and their oxidation states in ZnO flowers, XPS study was carried out. The binding energy peaks of $\mathrm{Zn}$ and $\mathrm{O}$ are shown in XPS spectrum (Fig. 3a). No peaks of other elements can be observed. In Fig. $3 \mathrm{~b}$, the $\mathrm{O}_{1 \mathrm{~s}}$ profile found to be asymmetric in nature and can be deconvoluted into to three peaks locating at 529.9, 531.4 and $532.3 \mathrm{eV}$, respectively, indicating three different kinds of $\mathrm{O}$ species in the sample. The peak centered at $529.9 \mathrm{eV}$ is closely associated with the lattice oxygen $\left(\mathrm{O}_{\mathrm{L}}\right)$ of $\mathrm{ZnO}$, the peak at $531.4 \mathrm{eV}$ is attributed to the oxygen of surface hydroxyl $\left(\mathrm{O}_{\mathrm{H}}\right)$, while the peak at $532.3 \mathrm{eV}$ is due to the chemisorbed oxygen $\left(\mathrm{O}_{\mathrm{a}}\right)$. It has been shown that surface hydroxyls $(\mathrm{OH})$ of the photocatalyst play a significant role for a photocatalytic oxidation process. ${ }^{33} \mathrm{Fig}$. $3 \mathrm{c}$ presents the XPS spectra of $\mathrm{Zn} 2 \mathrm{p}$, and the peak positions of $\mathrm{Zn}$

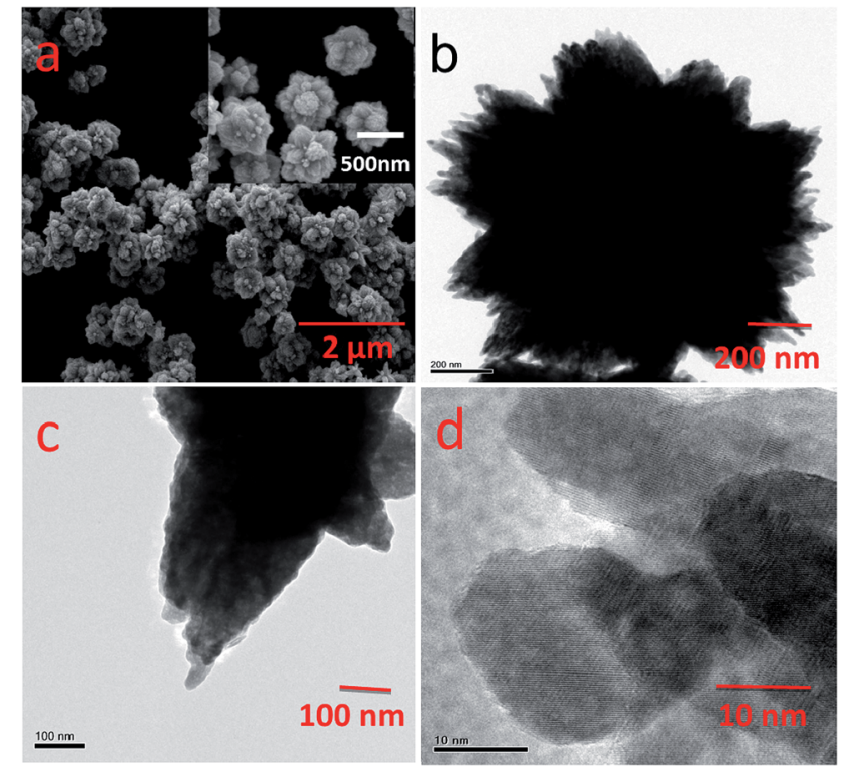

Fig. 2 (a) SEM (b, c) TEM micrographs (d) HRTEM micrograph of hierarchical $\mathrm{ZnO}$ flowers. 

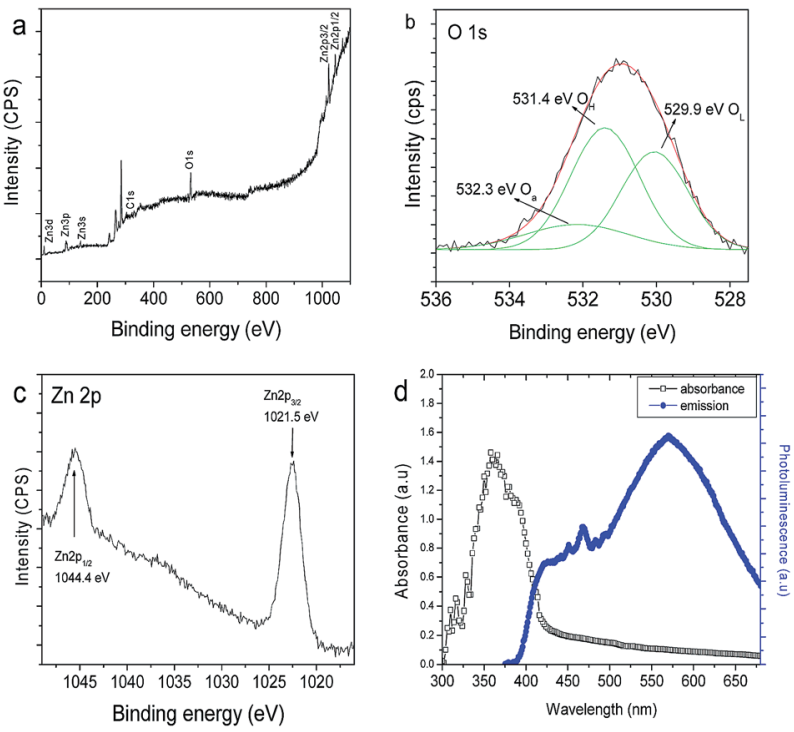

Fig. 3 XPS spectra of as synthesised flower like $\mathrm{ZnO}$ (a) survey spectrum, (b) O 1s peak, (c) Zn 2p peak and (d) absorbance and luminescence spectra of hierarchical $\mathrm{ZnO}$ flower structures.

$2 \mathrm{p}_{1 / 2}$ and $\mathrm{Zn} 2 \mathrm{p}_{3 / 2}$ are at $1044.4 \mathrm{eV}$ and $1021.5 \mathrm{eV}$ respectively and the different between the two peaks are 23.1 indicating that $\mathrm{Zn}$ is in the $\mathrm{Zn}^{2+}$ valence state. ${ }^{34}$

\section{Optical properties}

Fig. 3d shows the optical absorption and photoluminescence spectra of hierarchical $\mathrm{ZnO}$ flowers. ZnO shows a strong absorption of UV and has slight absorption in the visible region of light. This reveals that ZnO can be used as a UV and visible light active semiconductor photocatalytic material (Fig. S4 $\dagger$ ). Room temperature PL spectra mainly consist of two emission bands: a band at $416 \mathrm{~nm}(2.98 \mathrm{eV})$ and a strong greenish band at $530 \mathrm{~nm}(2.34 \mathrm{eV})$. The strong UV emission at $416 \mathrm{~nm}$ corresponds to the electron-hole recombination from the CB to VB. ${ }^{35}$ The green emission is due to surface oxygen defects in $\mathrm{ZnO}$ flower like hierarchical structures. ${ }^{15}$ As the $\mathrm{ZnO}$ flowers have higher rate of oxygen vacancy states, it may have the photocatalytic degradation efficiency in the visible and UV region. ${ }^{15}$

\section{Photodegradation study}

Fig. 4 shows the photocatalytic degradation properties of asprepared hierarchical $\mathrm{ZnO}$ flowers structures against heteroaromatic MB. Hierarchical ZnO flowers show promising photocatalytic activity under UV and visible photo irradiation. Moreover, the variation in $\mathrm{MB}$ degradation efficiency is consistent with the different light irradiation used (Fig. 4a). As shown in Fig. 4a, the degradation efficiency is about $2.8 \%$, 98.8\%, 99.3 and 98.9\%, under dark, UV light, visible light and sunlight irradiation for $180 \mathrm{~min}$ respectively. In the case of visible light irradiation, $\mathrm{ZnO}$ exhibits better photocatalytic behaviour than other conditions and showed complete degradation $(98.4 \%)$ of $\mathrm{MB}$ in $120 \mathrm{~min}$.
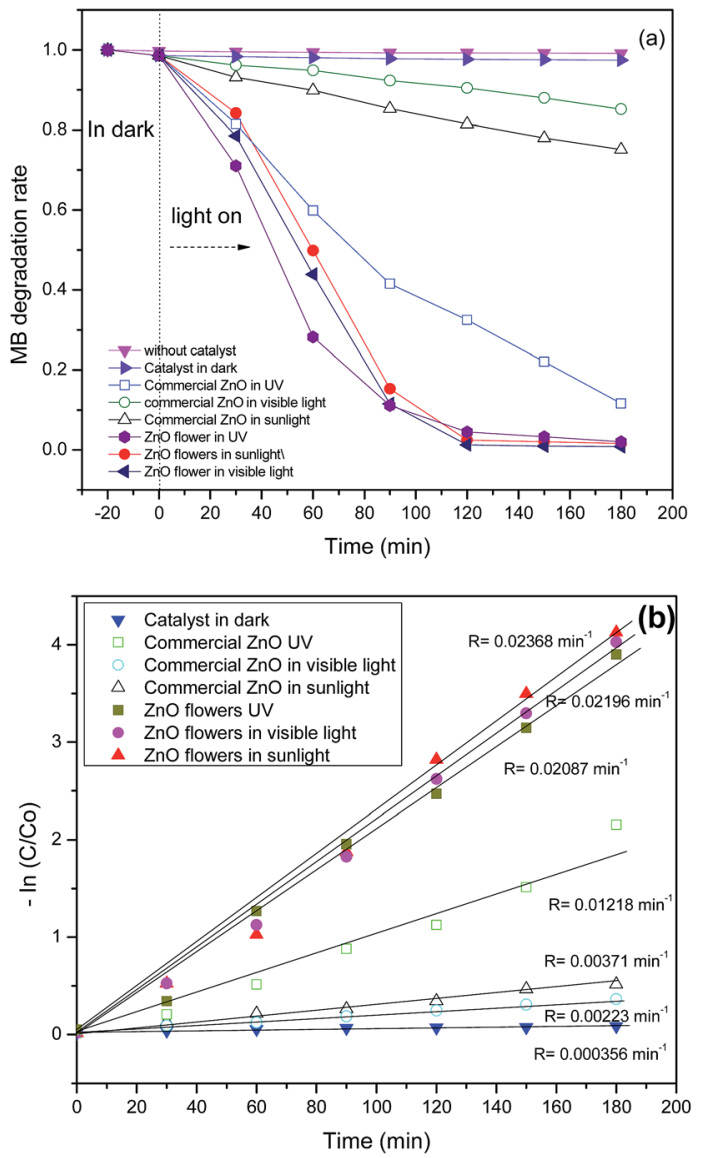

Fig. 4 Photocatalytic performance of as synthesised and commercial ZnO: (a) degradation efficiency and (b) degradation kinetics of MB dye solution under various photo illumination.

It is clear from the figure that the PC degradation performance of commercial $\mathrm{ZnO}$ varies with different irradiation. Commercial $\mathrm{ZnO}$ show maximum PC degradation efficiency about 58\% for $90 \mathrm{~min}$ against MB dye under UV illumination. Whereas, hierarchical ZnO flowers show relatively higher PC activity about 80 to $90 \%$ for $90 \mathrm{~min}$ against MB dye under UV, visible light and sun light irradiation. This clearly shows that hierarchical ZnO flowers exhibit higher degradation efficiency compared to that of commercial ZnO. The photocatalytic efficiency of the hierarchical ZnO flowers were compared with the commercially available $\mathrm{ZnO}$ hierarchical structures under different photo illumination sources and the degradation rate were calculated from the Fig. $4 \mathrm{~b}$. From the above experimental results, it is clear that the $\mathrm{ZnO}$ hierarchical flower has higher photocatalytic activity and more interestingly, it is found to be a suitable candidate for natural sunlight driven photocatalytic application. The photo degradation results show that (i) no notable degradation takes place without catalyst (ii) under dark conditions, mild adsorption of $\mathrm{MB}$ with $\mathrm{ZnO}$ is observed (iii) $\mathrm{ZnO}$ exposed to UV and visible light sources has excellent photocatalytic degradation activity, which degrade MB completely (98.2\%) in $120 \mathrm{~min}$. (iv) Optically active defect states play vital role in improving the visible photocatalytic properties and this has already conformed from our previous publication. ${ }^{15}$ 
Effect of $\mathrm{pH}$ role on dye solution was investigated since catalytic degradation efficiency varied with respect to $\mathrm{pH}$. Fig. 5 shows the effect of dye degradation efficiency at different $\mathrm{pH}$ from 3 to 11 for ZnO hierarchical structures under UV and visible irradiation. It is observed that the degradation rate increases with increase in $\mathrm{pH}$ up to 9 and then it decreases. Under $\mathrm{pH} 9$ the degradation rate is higher due to the catalyst zero point charge which increases the surface charge density of the catalyst thus making it negatively charged. ${ }^{34}$ It effectively increases the adsorption of dye molecules to the catalyst surface and promotes the interaction between the negatively charged catalysts with dye molecules and increases the electrostatic attraction between dye anions. A similar trend is observed with the commercial ZnO (Fig. 5c). To further confirm this, an experiment to find out the adsorption of dye in dark at different $\mathrm{pH}$ was carried out (figure not shown). The rate of adsorption of $\mathrm{MB}$ on the $\mathrm{ZnO}$ catalytic surface, after the attainment of adsorption equilibrium, are $0.04,0.74,1.46,5.74$ and $3.74 \%$ at $\mathrm{pH}$ 3, 5, 7, 9 and 11 respectively. ZnO hierarchical structures has high adsorbance of dye molecules at pH 9. At higher (above 11) and lower (below 7) pH, the electrostatic attraction between dye anions and negatively charged catalyst becomes weak resulting in reduced adsorption. Photo irradiation of hierarchical $\mathrm{ZnO}$ flower exhibits higher photocatalytic efficiency owing to its relatively higher surface area (Fig. S6†) and effective production of charge carriers on the catalyst surface. ${ }^{\mathbf{1 5}}$

\section{Photocatalytic degradation mechanism}

Under UV and visible light irradiation $\mathrm{ZnO}$ hierarchical flowers completely degraded the MB with the irradiation time of $180 \mathrm{~min}$. This can be due to the fact that the additional charge carriers $\left(\mathrm{e}^{-} / \mathrm{h}^{+}\right)$and more reactive species $\left(\mathrm{OH}^{-}\right)$are generated in the system as a result of the successive absorption of visible light photons by $\mathrm{ZnO}$. As the band gap of $\mathrm{ZnO}$ does not lie in the visible region $(>3.2 \mathrm{eV})$, it is evident that oxygen related defect states effectively play a vital role in superior visible light photo absorption behaviour thus showing efficient photocatalytic ability in the visible region (Fig. S7†). ${ }^{\mathbf{1 0 1 5}}$ The possible photo degradation mechanism of the organic pollutant was explained in our previous manuscript. ${ }^{15}$ Upon visible light irradiation, electron-hole pairs are generated and the photo generated electrons $\left(\mathrm{e}^{-}\right)$occupy the lower edge of the conduction band (CB) and the positive holes $\left(\mathrm{h}^{+}\right)$at the upper edge of the valance band (VB). ${ }^{36,37}$ Thus, the generated charge carriers can either recombine (not favourable to photocatalysis) or rapidly diffuse to the surface of $\mathrm{ZnO}$ serving as redox sources. The holes in the $\mathrm{VB}$ are readily scavenged by hydroxyl $\left(\mathrm{OH}^{-}\right)$ions (hole acceptor) leading to hydroxyl radicals $\left(\mathrm{OH}^{*}\right)$ and the photo excited
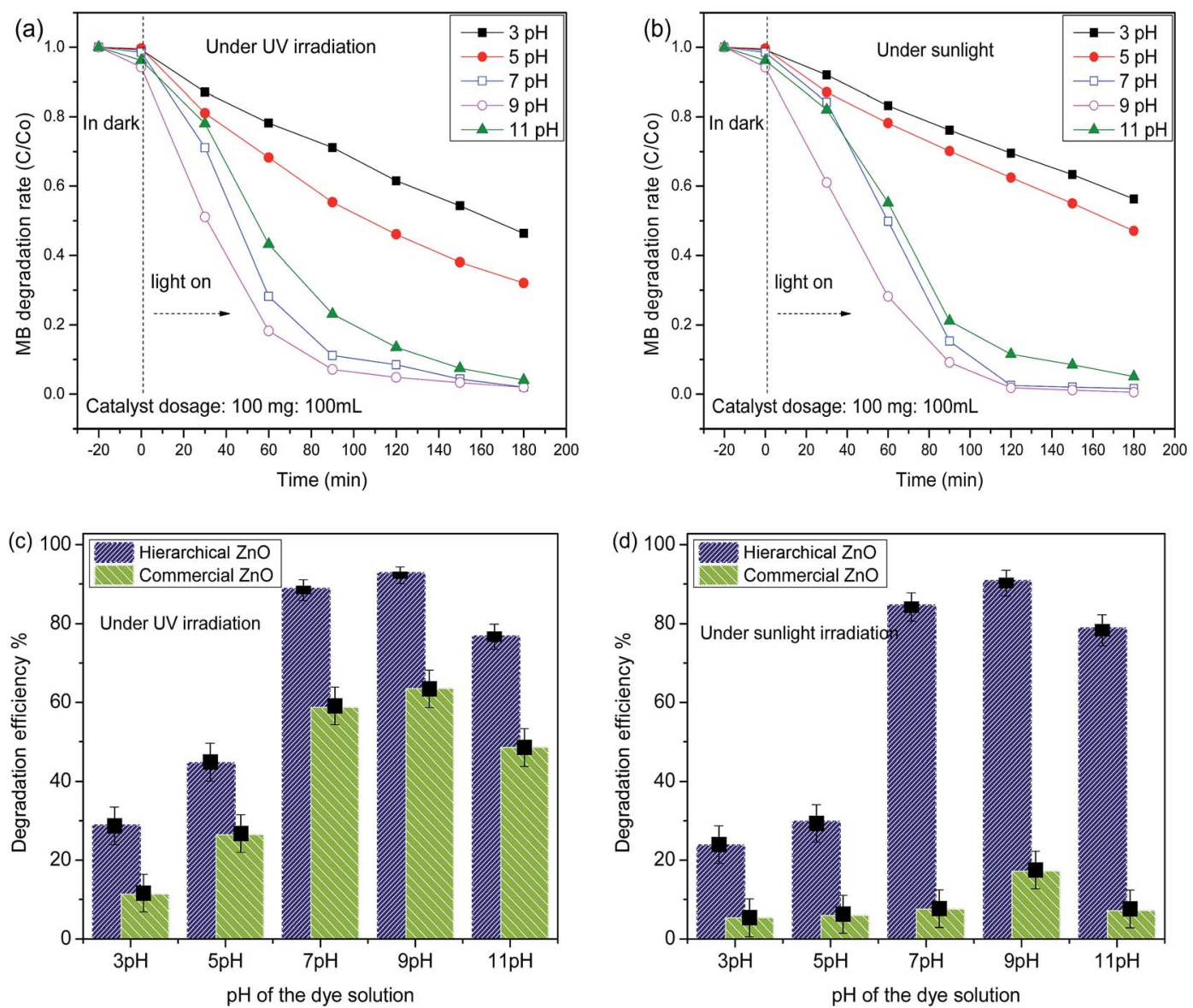

Fig. 5 Effect of pH on the photocatalytic performance of hierarchical ZnO flowers respective with time under (a) UV and (b) sunlight irradiation and comparison with commercial ZnO catalyst under (c) UV and (d) sunlight irradiation in 90 min. 
electrons in the $\mathrm{CB}$ are scavenged by lattice oxygen $\left(\mathrm{O}_{2}{ }_{2}\right.$ electron acceptor) through $\mathrm{H}_{2} \mathrm{O} / \mathrm{OH}^{-}$to form superoxide radicals $\left(\mathrm{O}_{2}{ }_{2}\right)$ (eqn (2) and (3)). ${ }^{38}$

$$
\begin{gathered}
\mathrm{ZnO}\left(\mathrm{h}^{+}\right)+\mathrm{OH}^{-} \rightarrow \mathrm{ZnOOH}(\mathrm{abs}) \\
\mathrm{ZnO}\left(\mathrm{e}^{+}\right)+\mathrm{O}_{2} \rightarrow \mathrm{ZnOO}_{2}(\mathrm{abs}) \\
\mathrm{O}_{2}^{\cdot}+\mathrm{H}^{+} \leftrightarrow \mathrm{HO}^{2-} \\
\mathrm{O}_{2}^{\cdot}+\mathrm{H}_{2} \mathrm{O} \rightarrow \mathrm{HO}_{2}^{\cdot}+\mathrm{OH}^{-} \\
\mathrm{HO}_{2}^{\cdot}+\mathrm{H}_{2} \mathrm{O} \rightarrow \mathrm{H}_{2} \mathrm{O}_{2}+\mathrm{OH}^{\cdot}
\end{gathered}
$$

Fig. 6 shows the reactive oxygen species production under UV and visible irradiation for hierarchical ZnO flowers. Super oxides are the major productive reactive oxygen species on $\mathrm{ZnO}$ system under photo irradiation. ${ }^{39}$ Super oxides were highly evolved under solar irradiation as compared to UV illumination and the results were in corroboration with its photocatalytic properties. The newly formed superoxide radicals $\left(\mathrm{O}_{2}{ }^{\circ}\right)$ further react with $\mathrm{h}^{+}$, and $\mathrm{H}_{2} \mathrm{O}$ and produce increased number of $\mathrm{OH}^{-}$ in solution which leads to rapid oxidation of MB (Fig. S8†). Fig. 7 display the trapping experiment of the active species during the photocatalytic reaction of commercial $\mathrm{ZnO}$ and hierarchical ZnO flower respectively. Fig. 7 shows that the PC degradation efficiency of commercial $\mathrm{ZnO}$ and hierarchical $\mathrm{ZnO}$ flowers against $\mathrm{MB}$ dye for $90 \mathrm{~min}$ under UV irradiation. Commercial ZnO show PC degradation efficiency about 58\% and hierarchical ZnO flowers show relatively faster degradation about $89 \%$ for 90 min (black bars, Fig. 7). It is interesting to see that the degradation efficiency of commercial $\mathrm{ZnO}(58 \%)$ decreased to $11 \%, 51 \%$ and $55 \%$ in the presence of super oxide (red bars), hydroxyl radical (blue bars) and hole (pink bars) quenchers respectively. The drastic decrease of PC efficiency
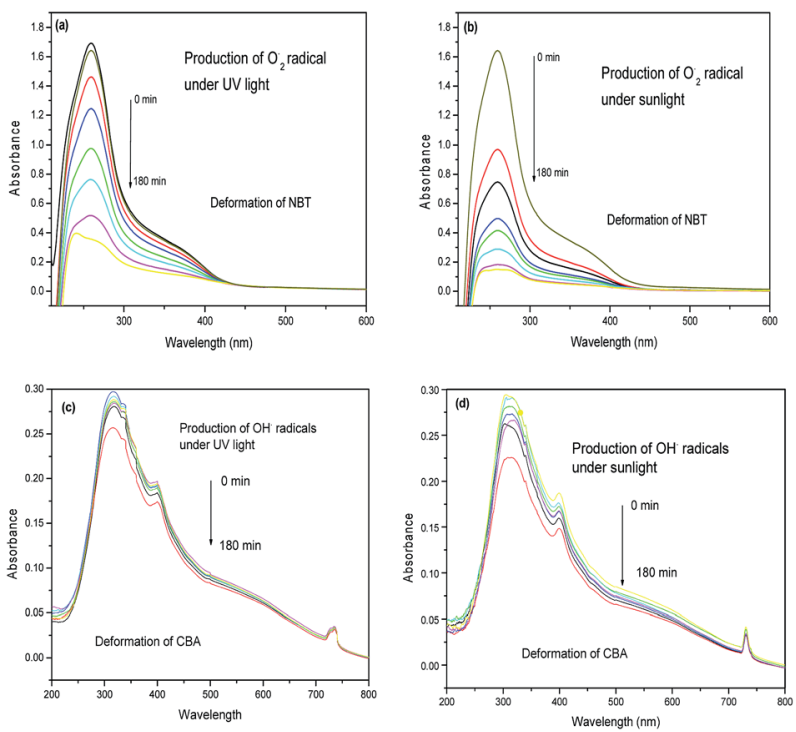

Fig. 6 Deformation of NBT and CPA with the presence of hierarchical ZnO flowers under different photo illumination $(a, c)$ in UV light and (b, d) in natural sunlight.

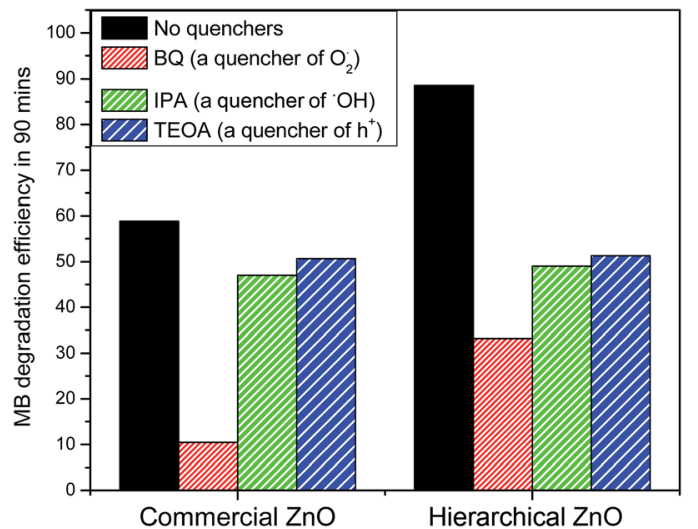

Fig. 7 Trapping of active species on commercial and hierarchical ZnO during the photocatalytic degradation of MB dye under UV irradiation for $90 \mathrm{~min}$.

(down to 11\%) in the presence of super oxide quencher (BQ) and a decrease in smaller extent in the presence of hydroxyl radical $(51 \%)$ and hole $(55 \%)$ quenchers indicate that photogenerated electrons are the dominant factor influencing the degradation process. Since quenching of superoxide species drastically reduces the PC degradation efficiency whereas quenching of hydroxide radical and hole producing does not influence the PC degradation efficiency. On the other hand, PC degradation efficiency of hierarchical ZnO flowers (89\%) substantially decreased to $31 \%, 49 \%$ and $52 \%$ in the presence of super oxide (red bars), hydroxyl radical (blue bars) and hole (pink bars) quenchers respectively. This indicate that both photogenerated electrons and holes are responsible for enhanced degradation efficiency of hierarchical ZnO flowers. This clearly shows that relatively more number of photogenerated holes are reaching to the surface in the case of hierarchical $\mathrm{ZnO}$ flowers compared to that of the commercial $\mathrm{ZnO}$ and thus show relatively higher PC efficiency.

\section{Reusability of the catalyst}

The reusability of hierarchical ZnO flowers was tested for the degradation of MB under identical reaction conditions. After complete degradation, the catalysts were separated and washed with deionized water. The recovered catalysts were dried and used for the next run. Fig. 8a shows the results of MB degradation for ten runs of the hierarchical ZnO structures. Hierarchical ZnO flowers exhibit MB degradation efficiency are 98.2$85.4 \%$ from $1^{\text {st }}$ to $10^{\text {th }}$ runs respectively for $180 \mathrm{~min}$. There is a significant change in the degradation efficiency of $\mathrm{ZnO}$ for $\mathrm{MB}$ dye after multiple cycles. In order to gain better understanding of the repeatable catalytic degradation, reusable catalytic performances were studied for 50 cycles. A drastic decrease in photocatalytic efficiency was found on increasing the reusable cycles above 10 .

Fig. 8b shows the reusable catalytic properties upto 50 cycles. Catalyst loss during multiple uses was avoided by quick precipitation in a specifically designed reactor. On increasing the number of cycles, the photocatalytic activity was found to 

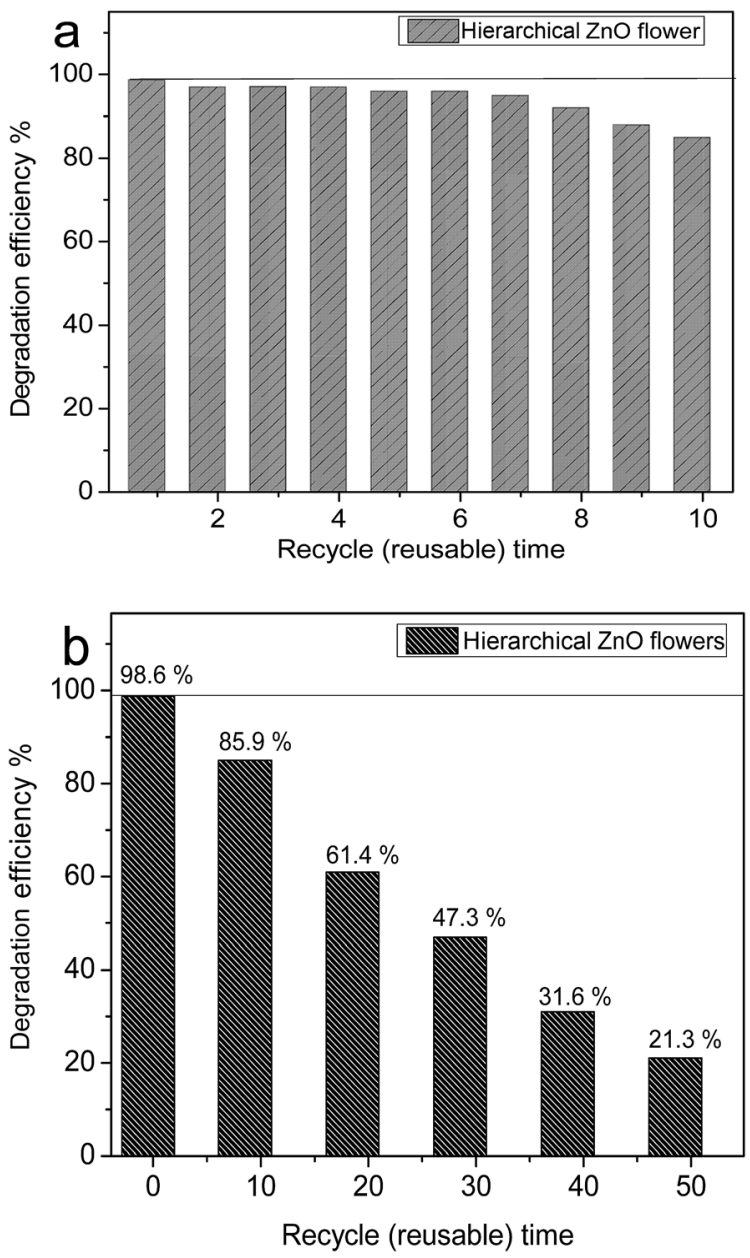

Fig. 8 Reusable degradation activity for $\mathrm{ZnO}$ flower (a) upto 10 cycles and (b) for upto 50 cycles (MB: $15 \mathrm{mg} \mathrm{L}^{-1}, \mathrm{ZnO}$ suspension $100 \mathrm{mg} / 100$ $\mathrm{mL}$, time $3 \mathrm{~h}$ ).

reduce due to the absorbance of degraded dye molecules onto the surface of $\mathrm{ZnO}$.

\section{Poisoning effect on catalytic surface}

Catalyst poisoning effect involves the compounds which bonds chemically to the active surface sites of a catalyst. ${ }^{21}$ Photogenerated charge carriers generates $\mathrm{H}_{2} \mathrm{O}_{2}$ and $\mathrm{OH}^{*}$ which interact with cationic sulfur group and hetero aromatic rings in $\mathrm{MB}$ and produce sulfoxide and intermediate products. These sulfoxide groups further oxidize to sulfone, causing the definitive dissociation of $\mathrm{MB}$ resulting in the formation of volatile low molecular weight compounds such as $\mathrm{CO}_{2}, \mathrm{H}_{2} \mathrm{O}$, $\mathrm{NH}_{4}{ }^{+}, \mathrm{NO}_{3}{ }^{-}$and $\mathrm{SO}_{4}{ }^{2-}$ ions. ${ }^{\mathbf{4 0 , 4 1}}$ For further understanding the catalyst poisoning effect, functional properties on hierarchical catalyst surface before and after degradation cycles, were investigated.

Fig. 9 shows the FTIR spectrum of a (i) pure MB dye solution (ii) $\mathrm{ZnO}$ hierarchical flowers before its use for photo degradation (iii) ZnO hierarchical flower catalyst after 10 cycles of photo degradation. The different functional groups associated with the $\mathrm{MB}$ absorption peaks are $\mathrm{H}-\mathrm{OH}$ stretching $\left(3428 \mathrm{~cm}^{-1}\right)$,
$\mathrm{CH}=\mathrm{N}\left(1600 \mathrm{~cm}^{-1}\right), \mathrm{C}=\mathrm{C}\left(1500-1400 \mathrm{~cm}^{-1}\right),-\mathrm{CH}_{2}$ or $-\mathrm{CH}_{3}$ (1400-1300 $\left.\mathrm{cm}^{-1}\right),-\mathrm{C}-\mathrm{N}\left(1254 \mathrm{~cm}^{-1}\right), \mathrm{N}-\mathrm{N}\left(1222 \mathrm{~cm}^{-1}\right),-\mathrm{C}-\mathrm{O}$ (1200-1000 $\left.\mathrm{cm}^{-1}\right)$ and $-\mathrm{N}-\mathrm{O}\left(947 \mathrm{~cm}^{-1}\right)$ the main chromophores. ${ }^{42}$ The magnified view of the spectra reveal the emergence of $\mathrm{C}=\mathrm{C}, \mathrm{C}=\mathrm{O}$ peaks ${ }^{43}$ around $1400 \mathrm{~cm}^{-1}$ and $1000 \mathrm{~cm}^{-1}$ for the reused $\mathrm{ZnO}$ flowers compared to the unused $\mathrm{ZnO}$ hierarchical flowers indicating the adsorption of degraded molecules on the ZnO hierarchical flowers. The chemisorbed carboxylate groups on ZnO surface (Fig. 9b) decreases the degradation efficiency on increasing the number of cycles of photocatalysis for more than 10 times.

\section{Regeneration of hierarchical ZnO flower catalysts}

The photocatalytic performance of hierarchical $\mathrm{ZnO}$ catalysts could be regenerated by removing the adsorbed molecules from the surface of the catalyst. In our investigation, on increasing the $\mathrm{pH}$ of the dye solution, dye-catalyst interaction increased resulting in increase of both degradation efficiency and dye adsorption (Fig. 5). From the observations, at lower $\mathrm{pH}$, the dissolution rate of the catalyst was high as compared
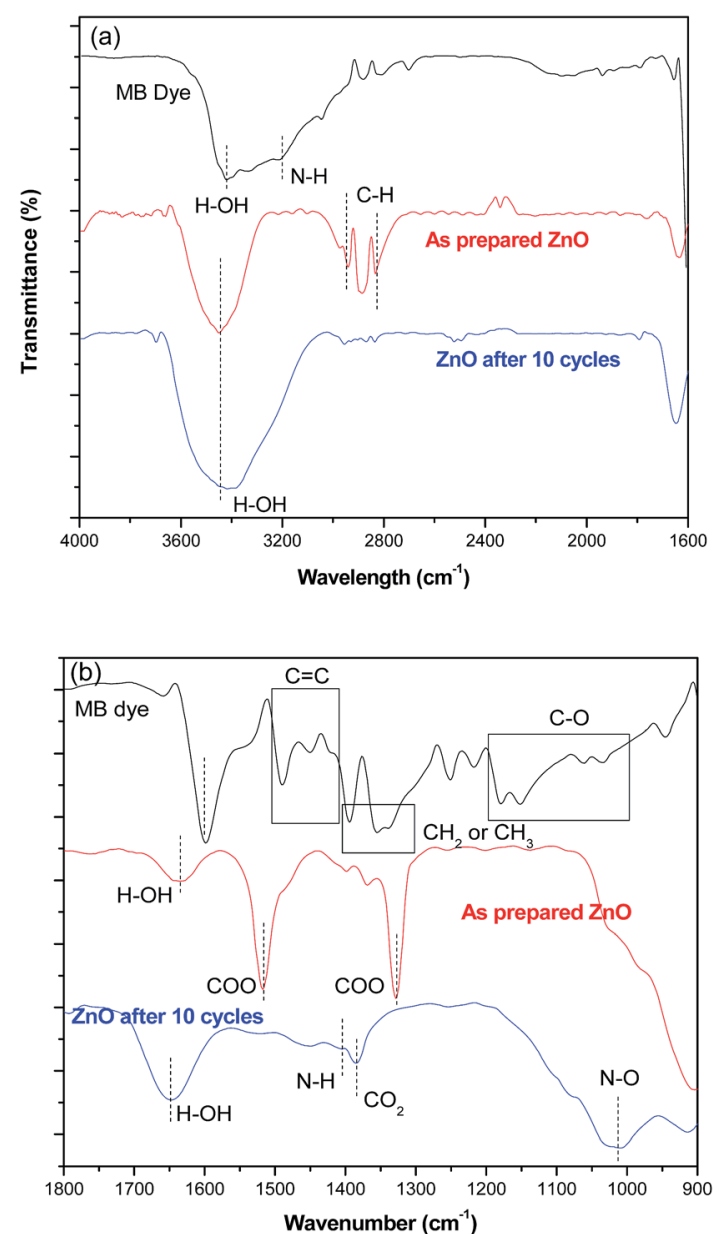

Fig. 9 FTIR spectra of $\mathrm{ZnO}$ flowers, before and after the degradation process under UV irradiation (a) ranges from $4000-1600 \mathrm{~cm}^{-1}$ and (b) ranges from $1800-900 \mathrm{~cm}^{-1}$. The pure $M B$ were used as a reference sample. 
to the higher $\mathrm{pH}$. Therefore, it is proposed to disperse the used catalyst in the lower $\mathrm{pH}$ solution to strip the adsorbed functional group from the active sites of the catalyst. Mild $\mathrm{HCl}$ acid treatment is proposed to remove the adsorbed dye molecules on the hierarchical catalyst surface. Parameters such as concentration of the acid and the treating time were optimized to remove the adsorbed dye molecules without damaging the ZnO hierarchical catalyst morphology. The hierarchical ZnO catalyst used consecutively for 50 degradation cycles were treated with $0.0001 \mathrm{M} \mathrm{HCl}$ acid for different time durations and their degradation performances are shown in Fig. 10. It is clear from the Fig. 10 that the photocatalytic performance of the $\mathrm{ZnO}$ hierarchical catalyst treated with $0.0001 \mathrm{M}$ of $\mathrm{HCl}$ for 20 min reverted to its maximum performance. The hierarchical catalyst treated for $5 \mathrm{~min}$ showed slower catalytic performance revealing that still the surface has some poisoning effect. Whereas increasing the treatment time to $40 \mathrm{~min}$ resulted in poor performance probably due to the adsorption of other functional groups and the higher erosion of catalyst surface. More detailed investigation is required for better understanding. Thus, $\mathrm{ZnO}$ hierarchical catalyst treated for $20 \mathrm{~min}$ is found to be optimum to nearly remove the adsorbed dye molecules to regain its maximum photocatalytic performance.

Fig. 11a and b shows the poisoned hierarchical ZnO flowers after mild $\mathrm{HCl}$ acidic treatment for $5 \mathrm{~min}$ and $20 \mathrm{~min}$ respectively compared with the poisoned $\mathrm{ZnO}$ catalyst. The intensity of the peaks in the range of $1400-1500 \mathrm{~cm}^{-1}$ that corresponds to the $\mathrm{C}=\mathrm{O}$ bonds decreased on increasing the duration of acid treatment. The peak at $1319 \mathrm{~cm}^{-1}$ and $1530 \mathrm{~cm}^{-1}$ that corresponds to $\mathrm{C}=\mathrm{O}$ and $\mathrm{O}-\mathrm{H}$ bending vibrations ${ }^{43}$ respectively diminishes gradually for acid treated catalysts. FTIR spectra significantly demonstrate that due to poisoning effect, more number of $\mathrm{C}=\mathrm{C}$ stretching bonds were adsorbed on $\mathrm{ZnO}$ catalyst which inactivates the catalytic surface. On treating the poisoned catalyst with mild acid, successful removal of the $\mathrm{C}=\mathrm{C}$ on the catalytic surface takes place and its catalytic activity is regained. With optimized concentration of acid cleaning, removal of the adsorbed toxic dye molecules from the catalyst

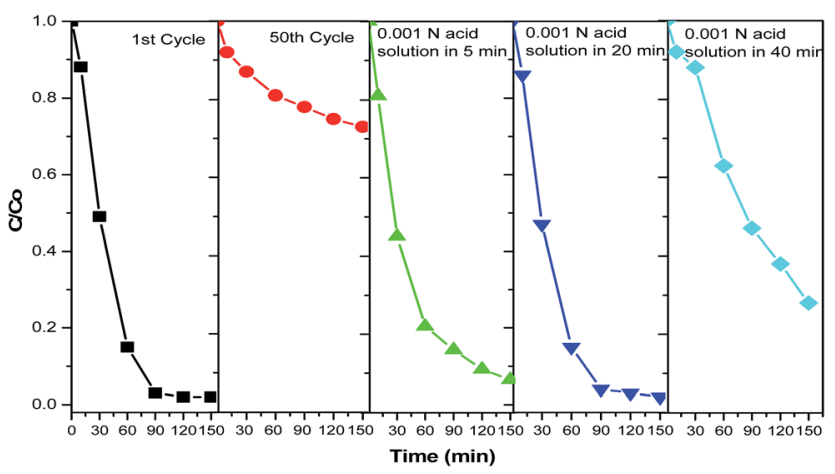

Fig. 10 Degradation of MB under UV irradiation in the presence of ZnO flowers (a) $1^{\text {st }}$ cycle, (b) $50^{\text {th }}$ cycle, (c) acid treatment of 5 min on 50 times reused catalyst, (d) acid treatment of 10 min on 50 times reused catalyst, and (e) acid treatment of $20 \mathrm{~min}$ on 50 time reused catalyst $(0.001 \mathrm{~N}$ of mild $\mathrm{HCl}$ were used for the acid treating).
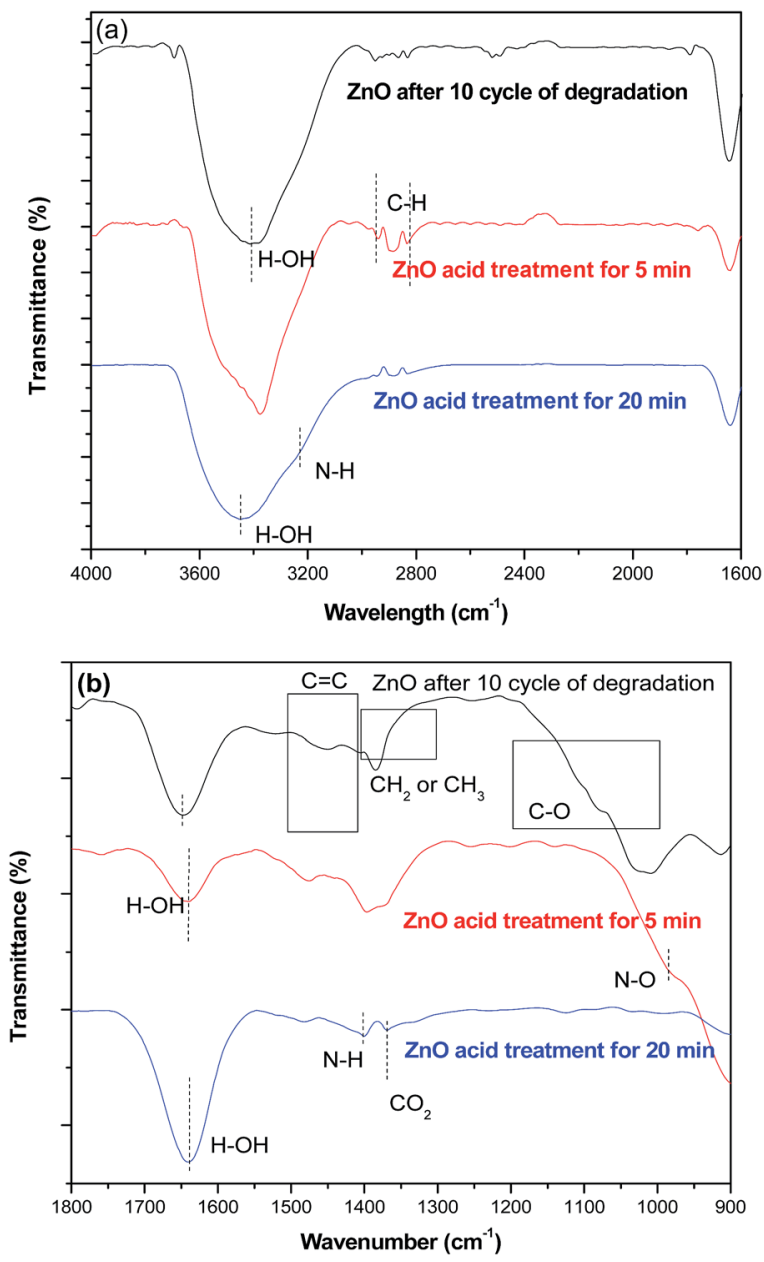

Fig. 11 FTIR spectra of ZnO flowers, before and after acid treatment for the removal of poisoning effect on the catalytic surface (a) ranges from $4000-1600 \mathrm{~cm}^{-1}$ and (b) ranges from $1800-900 \mathrm{~cm}^{-1}$.

surface is made possible and the catalyst regain its catalytic activity. In order to study the stability of ZnO, XRD and SEM analysis were performed for samples of pure hierarchical $\mathrm{ZnO}$ flowers before degradation and after degradation for many cycles (Fig. 12). It could be observed that the characteristic peaks for $\mathrm{ZnO}$ are identical for all the treated samples compared with the pure $\mathrm{ZnO}$ confirming its catalytic ability and phase stability.

Fig. 12a shows the XRD spectra of fresh and used ZnO PC (50 cycles). It was found that the crystal structure of ZnO PC did not change after 50 cycles and further acid/chemical treatment, indicating the stability of the PC. Hence the catalyst can be reused for continuous treatment of waste dye water. Further morphological investigation also revealed that there is no significant morphological change after photocatalytic and chemical treatment process. TEM images of the mild acid treated $\mathrm{ZnO}$ flowers does not shows any influence over the morphology of the hierarchical flowers after mild acid treatment (Fig. S9 $\dagger$ ). Further degradation studies on the regenerated hierarchical ZnO flowers showed in Fig. S10, ESI. $\dagger$ 

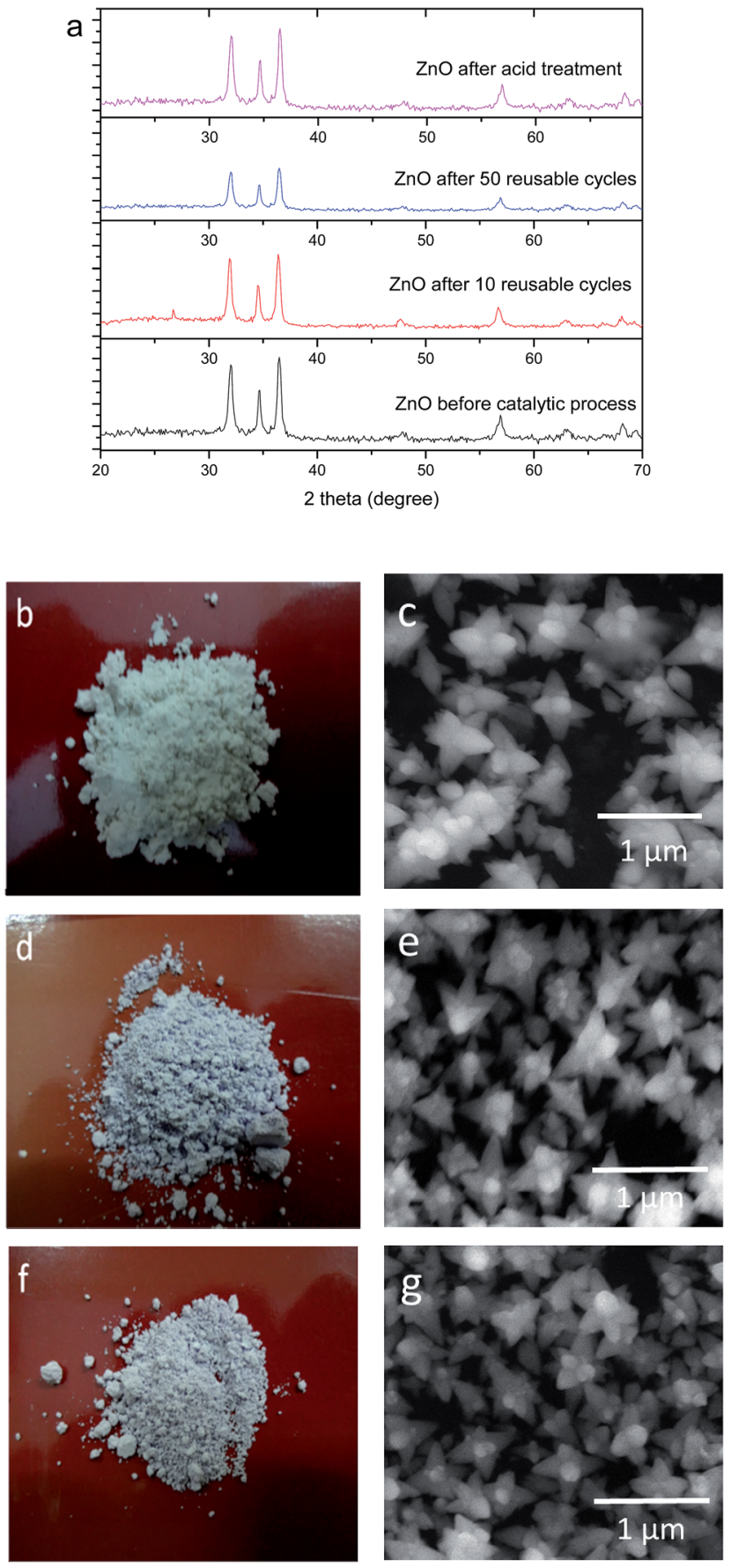

Fig. 12 Structural and morphological properties of $\mathrm{ZnO}$ flowers before, after photocatalytic reaction and after acid treatment (a) XRD pattern, $(b-g)$ optical and FESEM images of $\mathrm{ZnO}$ hierarchical flower. (b, c) as-prepared, (d, e) after 50 catalytic cycles and (f, g) after mild acid treatment.

\section{Conclusions}

In summary, solar and visible active hierarchical flower-like ZnO catalysts were synthesized by a solution-based process and reusable catalytic properties were studied upto 50 consecutive cycles. The optically active defects play a vital role in improving the photocatalytic properties during both UV and visible irradiation. After 8 reusable cycles the $\mathrm{ZnO}$ flower shows detraction on its catalytic efficiency and nearly lose its catalytic ability by 50 cycles due to the adsorption of hydrocarbon groups over the active sites. Controlled chemical treatment revert the maximum catalytic performance by stripping the adsorbed functional groups from the surface active sites for repeatable usage.

\section{Acknowledgements}

The authors KSR and RTR would like to thank the Department of Science and Technology, Government of India, for financial support under the Nano Mission Project (SR/NM/NS-113/2010BU (G)).

\section{References}

1 M. R. Hoffman, S. T. Martin, W. Choi and D. W. Bahnemann, Chem. Rev., 1995, 95, 69-96.

2 K. Bin and S. S. Madej, Ozone: Sci. Eng., 2012, 34, 136-139.

3 B. Ning, N. Graham, Y. Zhang, M. Nakonechny and M. G. ElDin, Ozone: Sci. Eng., 2007, 29, 153-176.

4 J. Yu and A. Kudo, Adv. Funct. Mater., 2006, 16, 2163-2169.

5 S. Kohtani, J. Hiro, N. Yamamoto, A. Kudo, K. Tokumura and R. Nakagaki, Catal. Commun., 2005, 6, 185-189.

6 M. Izadifard, G. Achari and H. L. Cooper, Catalysts, 2013, 3, 726-743.

7 Y. Yang, T. Zhang, L. Le, X. Ruan, P. Fang, C. Pan, R. Xiong, J. Shi and J. Wei, Sci. Rep., 2014, 4, 7045.

8 C. Lizama, J. Freer, J. Baeza and H. D. Mansilla, Catal. Today, 2002, 76, 235-246.

9 X. Pian, B. Lin, Y. L. Chen, J. D. Kuang, K. Z. Zhang and L. M. Fu, J. Phys. Chem. C, 2011, 115, 6531-6539.

10 J. Wang, Z. Wang, B. Huang, Y. Ma, Y. Liu, X. Qin, X. Zhang and Y. Dai, ACS Appl. Mater. Interfaces, 2012, 4, 4024-4030.

11 S. Baruah, R. F. Rafique and J. Dutta, Nano, 2008, 3, 399-407.

12 M. Y. Guo, A. M. Ching Ng, F. Liu, A. B. Djurišić, W. K. Chan, H. Su and K. S. Wong, J. Phys. Chem. C, 2011, 115, 1109511101.

13 D. Chen, Z. Wang, T. Ren, H. Ding, W. Yao, R. Zong and Y. Zhu, J. Phys. Chem. C, 2014, 118, 15300-15307.

14 H. W. Jeong, S. Y. Choi, S. H. Hong, S. K. Lim, D. S. Han, A. A. Wahab and H. Park, J. Phys. Chem. C, 2014, 118, 21331-21338.

15 K. S. Ranjith and R. T. Rajendrakumar, J. Photochem. Photobiol., A, 2016, 329, 35-45.

16 J. Wang, J. Yang, X. Li, D. Wang, B. Wei, H. Song, X. Li and S. Fu, Phys. E, 2016, 75, 66-71.

17 A. Snyder, Z. Bo, R. Moon and L. Stanciu, J. Colloid Interface Sci., 2013, 399, 92-98.

18 B. Subash, B. Krishnakumar, M. Swaminathan and M. Shanthi, Langmuir, 2013, 29, 939-949.

19 C. H. Bartholomew, P. K. Agrawal and J. R. Katzer, Adv. Catal., 1982, 31, 135-242.

20 M. D. Argyle and C. H. Bartholomew, Catalysts, 2015, 5, 145269. 
21 J. Liqiang, X. Baifu, Y. Fulong, W. Baiqi, S. Keying, C. Weimin and F. Honggang, Appl. Catal., A, 2004, 275, 4954.

22 L. A. Arrua, B. J. McCoy and J. M. Smith, Ind. Eng. Chem. Res., 1990, 29, 1050-1057.

23 B. Barrocas, O. C. Monteiro, M. Jorgea and S. Sério, Appl. Surf. Sci., 2013, 264, 111-116.

24 S. Adhikari, D. Sarkar and G. Madras, RSC Adv., 2015, 5, 11895-11904.

25 M. J. Jacinto, F. P. Silva, P. K. Kiyohara, R. Landers and L. M. Rossi, ChemCatChem, 2012, 4, 698-703.

26 H. D. Lasa, B. Serrano and M. Salaices, Photocatalytic Reaction Engineering, Springer, USA, 2005.

27 M. A. Halabi, J. Beshara and H. Qabazard, Catalysts in Petroleum Refining and Petrochemical Industries, Elsevier, 1996.

28 K. S. Ranjith, R. Pandian, E. McGlynn and R. T. Rajendra Kumar, Cryst. Growth Des., 2014, 14, 2873-2879.

29 L. Ye, K. Deng, F. Xu, L. Tian, T. Peng and L. Zan, Phys. Chem. Chem. Phys., 2012, 14, 82-85.

30 C. Ding, F. Cao, L. Ye, K. Liu, H. Xie, X. Jin and Y. Su, Phys. Chem. Chem. Phys., 2015, 17, 23489-23495.

31 H. Huang, S. Wang, Y. Zhang and P. K. Chub, RSC Adv., 2014, 4, 41219-41227.

32 K. Rajavel, R. Gomathi, S. Manian and R. T. Rajendra Kumar, Langmuir, 2014, 30, 592-601.
33 C. Tian, Q. Zhang, A. Wu, M. Jiang, Z. Liang, B. Jiang and H. Fu, Chem. Commun., 2012, 48, 2858-2860.

34 D. K. Mishra, P. Kumar, M. K. Sharma, J. Das, S. K. Singh, B. K. Roul, S. Varma, R. Chatterjee, V. V. Srinivasu and D. Kanjilal, Phys. B, 2010, 405, 2659-2663.

35 S. Balachandran, S. G. Praveen, R. Velmurugan and M. S. Swaminathan, RSC Adv., 2014, 4, 4353-4362.

36 A. Akyol, H. C. Yatmaz and M. Bayramoglu, Appl. Catal., B, 2004, 54, 9-24.

37 S. Bingham and W. A. Daoud, J. Mater. Chem., 2011, 21, 2041-2050.

38 K. Kabra, R. Chaudhary and R. L. Sawhney, Ind. Eng. Chem. Res., 2004, 43, 7683-7696.

39 Y. Li, W. Zhang, J. Niu and Y. Chen, ACS Nano, 2012, 6, 51645173.

40 L. Li, M. Krissanasaeranee, S. W. Pattinson, M. Stefik, U. Wiesner, U. Steiner and D. Eder, Chem. Commun., 2010, 46, 7620-7622.

41 F. Huang, L. Chen, H. Wang and Z. Yan, Chem. Eng. J, 2010, 162, 250-256.

42 M. L. Chen, F. J. Zhang and W. C. Oh, J. Korean Ceram. Soc., 2008, 45, 651-657.

43 http://www2.ups.edu/faculty/hanson/Spectroscopy/IR/ IRInterpretation.htm. 